\title{
BOLUS INTRAVENOUS NITROGLYCERIN FOR ST-SEGMENT DEPRESSION NOT ASSOCIATED WITH INCREASED MYOCARDIAL OXYGEN DEMAND
}

\author{
Ercument A. Kopman and Arthur F. Del Real
}

\begin{abstract}
Ischaemic ST-segment changes may occur in patients with coronary artery disease when myocardial oxygen consumption is increased as a result of hypertension, tachycardia or increased contractility. Ischacmia can also occur as the result of decreased coronary perfusion pressure caused by hypotension or coronary artery spasm. We report ST-segment depression in the absence of hypertension, tachycardia or hypotension. The response to bolus intravenous nitroglycerin suggested coronary artery spasm as the cause.
\end{abstract}

KEY WORDS: HEART, ischaemia, coronary artery spasm, nitroglycerin.

FOR MANY YEARS it was believed that myocardial ischaemia and/or ST-segment change were chiefly the result of increased oxygen demand rather than coronary arterial spasm. 'Recently, however, coronary artery spasm (usually superimposed on arteriosclerotic ${ }^{2,3}$ of even radiographically normal coronary arteries) $)^{4-7}$ has been shown clearly to be a significant factor contributing to angina at rest. The haemodynamic pattern observed in these patients has been described by Guazzi, et al. ${ }^{8}$ and Maseri, et al. ${ }^{9}$, who noted in particular that the onset of the ST-segment change was never preceded by an increase in heart rate and systolic blood pressure. Our case is in agreement with the definition of angina at rest of Prinzmetal and Maseri: ST-segment change (depression or elevation) $)^{9-28}$ without tachycardia or hypertension.

This report suggests that ischaemic ST-segment changes without an apparent precipitating factor such as hypertension, tachycardia, or hypotension may be considered and treated as coronary arterial spasm.

\section{REPORT OF A CASE}

A 39-year-old male was admitted to the hospital because of chest pains occurring at rest as well as during exercise. A coronary angiogram revealed 80 per cent occlusion of left

Ercument A. Kopman, M.D., Associate Professor; Arthur F. del Real, M.D., Resident; Department of Anesthesiology, Washington University School of Medicine, 660 South Euclid, St. Louis, Missouri, 63110.

Can. Anaesth. Soc. J., vol. 29, no. 6, November 1982 anterior descending (LAD) and the anterolateral branch of the same artery with normal ejection fraction ratio and normal ventricular function. He had been on propranolol (40 mg q.i.d.) and sublingual nitroglycerin. He was scheduled for single coronary bypass operation. Premedication consisted of morphine $10 \mathrm{mg}$ and scopolamine $0.4 \mathrm{mg}$ intramuscularly one hour before operation. Propranolol and nitroglycerin were continued to the time of operation. Anaesthesia was induced with diazepam $10 \mathrm{mg}$ and thiopentone $250 \mathrm{mg}$, and was then maintained with nitrous oxide and oxygen (50:50) and morphine sulphate $1.5 \mathrm{mg} \cdot \mathrm{kg}^{-1}$. Tracheal intubation was facilitated with pancuronium $10 \mathrm{mg}$. Arterial pressure, central venous pressure (CVP), pulmonary artery pressure (PAP), pulmonary capillary wedge pressure (PCWP) and heart rate remained stable after intubation and did not change after skin incision (left leg).

Approximately 30 minutes after induction and before thoracotomy, when arterial pressure, CVP, PA, PCWP and heart rate were unchanged (Figure 1, A), a sudden ST-segment depression occurred in lead $\mathrm{V}_{5}$. Following this, arterial pressure fell from $130 / 85-100 / 80$ torr with a concommittant rise in PAP and PCWP (Figure 1, B). Blood gases were normal.

Since ST-segment change was not preceded by an increase in heart rate or systolic pressure, coronary arterial spasm was assumed and a bolus of nitroglycerin $200 \mu \mathrm{g}(1 \mathrm{ml})$ was administered intravenously. Within a few minutes the ST-segment returned to base line, arterial pressure increased, PAP and PCWP returned to normal 


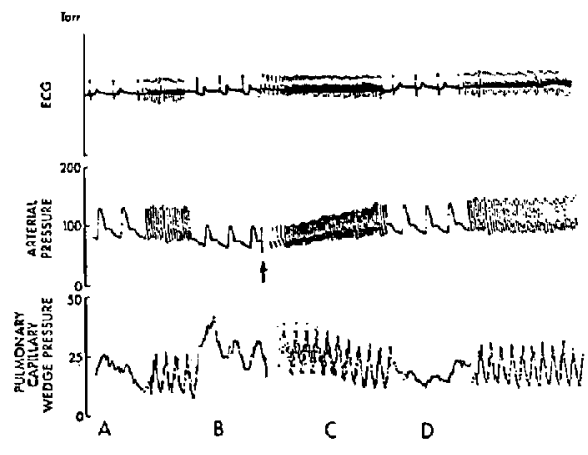

FIGURE 1. (A) Before the onset of ST change, normal ECG, arterial pressure and PA-PCWP. (B) Sudden ST change with a moderate decrease in arterial pressure and elevated PA-PCWP. ( $\uparrow$ ) $200 \mu \mathrm{g}$ intravenous nitroglycerin. (C) After nitroglycerin, arterial pressure increased paradoxically; PA-PCWP begin to decrease. (D) Normal EKG, arterial pressure and PA-PCWP

controls (Figure 1, C and D). The same sequence of ST-segment depression followed by a fall in arterial pressure and rise in PAP and PCWP occurred twice before cardiopulmonary bypass was begun and was treated successfully with bolus nitroglycerin as before.

\section{Discussion}

In patients with coronary artery disease, $\mathrm{ST}$ segment changes (depression or elevation) may occur during the course of anaesthesia when elevation of heart rate, blood pressure, contractility, or all three, increase myocardial oxygen demand. Myocardial ischaemia results when these increases exceed restricted myocardial supply. Ischaemic ST changes can occur also as the result of a decrease in coronary blood flow due to either diminished coronary perfusion pressure (hypotension) or increased coronary vascular resistance (spasm). In our case, the sequence of events in haemodynamic and EKG changes strongly suggested that a decrease in oxygen delivery was involved rather than increased oxygen demand.

ST-segment depression was not preceded by an elevation of systolic blood pressure; therefore ischaemia could not be attributed to increased oxygen demand produced by hypertension. Guazzi et al. ${ }^{8}$ have found that patients with variant angina do not exhibit an increase in the pressure-time index before angina, and that blood pressure, in fact, often decreases during the period of ST-segment change.
Since there had been no change in heart rate before the onset of St-segment changes, tachycardia was not the precipitating factor. One might speculate that ischaemia might have been preceded by increased contractility since $\mathrm{dp} / \mathrm{dt}$ was not measured before, during, or after STsegment alteration. However, if increased contractility (or sympathetic tone) had been the cause of ischaemia, ST-segment depression should have been preceded by an elevation of arterial pressure.

ST-segment change was not preceded by an increase in PCWP (or LVEP); therefore high PCWP observed after ST-segment depression was the result of ischaemia but not the cause (Figure 1, B). Ischaemia, then, could not be attributed to increased preload and wall tension. Nitroglycerin administration, which resulted in normalizing PCWP, was probably also a contributing factor in restoring myocardial oxygen balance by decreasing wall tension in addition to relieving spasm.

Since there was no hypotension before ST change, ischaemia was not initiated by a decrease in coronary perfusion pressure. Systolic and diastolic pressure dropped from 130/85 to $110 / 80$ torr after the onset of ischaemic ST-segment change (Figure 1, B). Decrease in diastolic pressure, although not significant, was thus also the result of diminished contractility produced by ischaemia but not the cause.

Although the true cause of coronary artery spasm is unknown, several factors have been proposed, such as reflex sympathetic activity, ${ }^{12.13} \beta$-receptor blockade by propranolol, ${ }^{14}$ hyperventilation, ${ }^{15}$ local thromboxane release by platelets, ${ }^{16,17}$ and ergonovine test ${ }^{18}$ (a provocative test to induce and detect coronary artery spasm).

The haemodynamic changes associated with typical angina pectoris have been emphasized in many reports and it is generally agreed that most anginal attacks are preceded by an increase in myocardial oxygen demand (increase of heart rate and/or systemic arterial pressure). In recent years, however, coronary artery spasm has taken on new importance as a likely contributor to typical angina pectoris and myocardial infarction in which the episode of ST-segment and T-wave abnormalities was not preceded by an increase in the haemodynamic determinants of myocardial oxygen demand. ${ }^{2-8}$

More recently, convincing evidence that coronary artery spasm may be a very common cause of angina pectoris comes from a series of 
carefully performed coronary arteriographic studies in patients with angina pectoris by Maseri, et al. ${ }^{9-18}$ In this group of patients, STsegment abnormalities were seldom preceded by an increase in the haemodynamic determinants of myocardial oxygen demand.

Although coronary artery spasm has been shown to occur in association with the common manifestations of coronary artery disease, its frequency as a major causal factor in the clinical occurrence of angina pectoris is not clear. However, in view of the possible role of coronary artery spasm in the genesis of typical angina pectoris, some therapeutic agents capable of alleviating such spasm are worthy of trial.

Calcium-channel blocking agents, a new group of powerful coronary vasodilators (nifedipine, ${ }^{19-20}$ verapamil, ${ }^{21,22}$ perhexilene, ${ }^{23,24}$ and diltiazem ${ }^{16}$ ) have been shown to be more effective than nitroglycerin in relieving coronary arterial spasm. However, the unavailability of these drugs in an intravenous form in this country limits their use during the course of anaesthesia.*

Although less effective than calcium-channel blocking agents, nitroglycerin is also beneficial in relieving coronary artery spasm. ${ }^{25-27} \mathrm{Vaso-}$ spasm induced by Ergonovine is usually reversible by sublingual or intravenous nitroglycerin. $25-27$

The detection of coronary artery spasm without angiographic evidence is difficult during the course of anaesthesia; however, sudden ST-segment elevation or depression ${ }^{9-28}$ associated with an unexplained reduction in arterial pressure as well as an increased in PCWP may indicate coronary arterial spasm and impaired contractility.

This report suggests that myocardial ischaemic changes (in the absence of hypertension and tachycardia) may be considered to be a result of coronary artery spasm and can be treated with a bolus of intravenous nitroglycerin.

\section{REFERENCES}

1. Friedberg, C.K. Diseases of the Heart. 3d ed Philadelphia, W.B. Saunders, (1966), 796-797

2. Hillis, L.D. \& BRaunwald, E. Coronary artery spasm. N. Engl. J. Med. 299: 695-702 (1978).

3. Neill, W.A., Ritzmann, L.W. \& Selden, R. The Pathophysiologic basis of acute coronary insufficiency: observations favoring the hypothe-

*Presently only verapamil (Isoptin ${ }^{8}$ ) is available in the intravenous preparation. Because of history of bradycardia, verapamil was not used in our patient. sis of intermittent reversible coronary obstruction. Am. Heart J. 94: 439-444 (1977),

4. Chen, T.O., Bashour, R., Kelser, G.A. JR, et al. Variant angina of Prinzmetal with normal coronary arteriograms: a variant of the variant. Circulation 47: 476-485 (1973).

5. Wiener, L., Kasparian, H., DUCa, P.R., et al. Spectrum of coronary arterial spasm: clinical angiographic and myocardial metabolic experience in 29 cases. Am. J. Cardio. 38: 945-955 (1976).

6. Higgins, C.B., Wexler, L., Silverman, J.F. et al. Clinical and arteriographic features of Prinzmetal variant angina: documentation of etiologic factors. Am. J. Cardiol. 37: 831-839 (1976).

7. Christian, N. \& Botti, R.E. Prinzmctal's variant angina pectoris with prolonged electrocardiographic changes in the absence of obstructive coronary disease. Am. J. Med. Sci. 263: 225-232 (1972)

8. Guazzi, M., Polese, A., Florentini, C., et al. Left ventricular performance and related hemodynamic changes in Prinzmetal's variant angina pectoris. Br. Heart J. 33: 84-94 (1971).

9. Maseri, A., Severi, S., Nes, M.D., et al. "Variant" angina: one aspect of a continuous spectrum of vasospastic myocardial ischemia: pathogenetic mechanisms, estimated incidence and clinical and coronary arteriographic findings in 138 patients. Am. J. Cardiol. 42: 1018-1035 (1978).

10. ABRAMS, J. Nitroglycerin and long-acting nitrates. N. Engl. J. Med. 302: 1234-1237 (1980).

11. Whiting, R.B., Klein, M.D., Vander Veer, J., et al. Variant angina pectoris. N. Engl. J. Med. 282: 709-712 (1970).

12. Yasue, H., Tourama, M., Kato, $\mathrm{H}$., et al. Prinzmetal's variant form of angina as a manifestation of alpha-adrenergic receptor-mediated coronary artery spasm: documentation by coronary arteriography. Am. Heart J. 91: 148-155 (1976).

13. Ricci, D.R., Orlick, A.E. Cipriano, P.R. et al. Altered adrenergic activity in coronary arterial spasm: insight into mechanism based on study of coronary hemodynamics and the electrocardiogram. Am. J. Cardiol. 43; 1073-1079 (1979).

14. KING, M.J., ZIR, L.M., KaltMan, A.J., et al. Variant angina associated with angiographically demonstrated coronary artery spasm and REM sleep. Am. J. Med. Sci. 265: 419-422 (1973).

15. Yasue, H., NaGao, M., Omote, S., et al. Coronary arterial spasm and Prinzmetal's variant form of angina induced by hyperventilation and Tris-buffer infusion. Circulation 58: 56-62 (1978).

16. Hirsh, P.D., Hillis, D., et al. Release of prostaglandins and tromboxane into the coronary circulation in patients with ischemic heart disease. N. Engl. J. Med. 304: 685-691 (1981).

17. LeWY, R.I., SMITH, J.B., Silver, M.J., et al. Detection of thromboxane $B_{2}$ in the peripheral blood of patients with Prinzmetal's angina. Prostaglandins Med. 2: 243-248 (1979)

18. Heupler, F.A., Proudfit, W.L., Razavi, M. et al. Ergonovine maleate provocative test for 
coronary artery spasm. Am. J. Cardiol. 41: 631-640 (1978).

19. Antman, E., Mullen, J., et al. Nifedipine therapy for coronary artery spasm. N. Engl. J. Med. 302: 1269-1273 (1980).

20. Mullen, J.E. \& Gunther, S.J. Nifedipine therapy for Prinzmetal's angina. Circulation 57: 137-139 (1978).

21. Solberg, L.E., Nissen, R.G., Vietstra, R.E. et al. Prinzmetal's variant angina-response to verapamil. Mayo Clin. Proc. 53: 256-259 (1978).

22. Johnson, S.M., Mautrson, D.R., et al. A controlled trial of verapamil for Prinzmetal's variant angina. N. Eng. J. Med. 304: 862-866 (1981).

23. Mizgala, H.F., Crittin, J., Waters, D.D., et al. Results of immediate and long term treatment of variant angina (VA) with perhexiline maleate. Circulation $59 \& 60$ : Supply 2: II-181, abstract (1979).
24. Mizgala, H.F., Chaitman, B.R., Theroux P., et al. Successful treatment of "variant angina" with oral perhexiline maleate. Circulation 53 \& 54: Suppl II-72, abstract (1976).

25. Hillis, L.D., \& Braunwald, E. Coronary artery spasm. N. Engl. J. Med. 299: 695-702 (1978).

26. SChroeder, J.S., BOLEN, J.L., QUint, R.A., $e t$ al. Provocation of coronary spasm with ergonovine maleate. Am. J. Cardiol. 40:487-491 (1977).

27. Curry, R.C., Pepine, C.J., Sabom, M.B., etal. Effects of ergonovine in patients with or without coronary artery disease. Circulation 56: 803-809 (1977).

28. Yasue, H., Omote, S., et al. Comparison of coronary arteriographic findings during angina pectoris associated with ST-elevation or depression. Am. J. Cardiol. 47: 539-546 (1981)

\section{RÉSUMÉ}

Des modifications de type ischémique du segment ST peuvent survenir chez les coronariens lorsque la consommation d'oxygène myocardique s'élève à cause d'une hypertension artérielle, d'une tachycardie ou d'une augmentation de la contractilité myocardique. L'Ischémie myocardique survient également lorsque la perfusion coronarienne est diminuée (hypotension artérielle ou spasm coronarien).

Nous rapportons un cas clinique de dépression du segment ST survenue en absence d'hypotension, d'hypertension et de tachycardie. Cette anomalie s'est corrigée à la suite de l'administration intraveineuse d'un bolus de $200 \mu \mathrm{g}$ de nitroglycérine, ce qui suggère qu'un spasme coronarien était à l'origine de cette modification du segment ST. 